dition, and that a crowding of such luminous matter involves an increase of luminosity, may we not infer with a high degree of probability that the strix are themselves aggregations of matter, and that the dark spaces between them are comparatively vacuous.

It is true that such a view of the case would seem to imply that, in gaseous media, the better the vacuum the more easily can the electricity pass; and that this might at first sight appear to be at variance with the known fact that the resistance of a tube decreases with the pressure until a minimum, determinate for each kind of gas, and then increases. Bnt it has been sug. gested by Edlund (Annales de Chemie et de Physique, i881, to n. iii. p. 199) that the resistance of a tube may really consist of two part-, first, that due to the pa-sage of the electricity tbrough the gas itself, and, secondly, th t due to it; passage from the terminals to the gas; and also that the former decreases, while the latter increases, as the pressure is lowered. On this supposition, the observed phenomena may be explained, without assigning any $\lim t$ to the facility with which electricity may traverse the mo:t vacuous space.

We may even carry the suggestion of a resistance of the second kind a little further, and :uppose that there is a resistance due to the passage of electricity frum a medium of one density to that of another, or from layer to layer of different degrees of yressure. And from this point of view, we may regard the stria as expressions of resistance due to the varying pressure in different parts of the tube. Into the question, whence tbis variation of pressure, I am not at present prepared to enter; it must suffice for thi; evening, to have shown that the conclusions which we have drawn from our experiments, are $n$ t in di accordance with other known phenomena of the electrical discharge.

The warning hand of time bids me not to prolong my discus. sion of the subject. But before closing, I would point out that these laborat ry experiments are not unsuggestive in reference to larger questions. It has long been, and still is, a disputed question whether a display of the aurora borealis ever takes place at any considerat.le elevation above the earth's surface. On the one hand, ob ervations are cited giving a not unfrequent elevation of nearly 200 miles; while on the oth $x$, experiments with vacuum tubes appear to limit the range to less than forty miles. The observation is perhaps a doubtful one at best; it is not easy to fix the position of so faint and flickering a pheno. menon, and it is perhaps even more difficult to' identify a particular phase of it when seen from two distant positions. But the recorded data are still entitle. 7 to some consideration, especially if it has been shown that the evidence furnished by vacuum tubes is not conclusive against the higher estimate.

It would be very pleasant, if, wafted by the breezes of scientific imagination, we were to set full sail, and navigate our bark into still more distant space. And, indeed, we are under no slight obligations to the strong minds and courageous spirits who thus adventure themselves out beyond well-known waters; for the treasures which they bring back from every such voyage are both valuable and strange, and they set men thinking on new and untrodden 1 nes. But lest, less fortu ate than my neighbours in any such venture, I should fail to fall in with a returning current, capable of recovering my expended energy, and of restoring myself to terra firma, I must here pause. It is, however, said, that in the mind of every one, even the most philosophic, there is a tender part; and therefore I must ask your indulgence, if, while resolutely turning my back on physical speculations, I still return for a moment to my first love, mathetnatical contemplation. For, in the region which we have been considering, namely, the magnetic field, explored and represented by its electric action, we seein to have entered ufon a world which Riemann might have longed to see, a world wherein Lobatcheffski and Beltrami might have enjoyed the full fruition of realised ideas, and where even Clifford might have found abundant scope for the exercise of his inexhaustible powers of imagination and of thought.

\section{FLORA OF NEW SOUTH WALES IN ITS} GEOLOGICAL ASPECT

THIS, the oldest of the Australian settlements, may have its area grouped as follows:- (I) That of the sundstones or poor country represented by the Proteads and Epacrids; (2) the eastern slopes of coast range represented by the tree-nettles and the palms; (3) the cold mountain shrubsure, resented by sassa- fras, tree ferns, and myrtles ; and (4) the interior $f$ lains repre sented by Chenopods and Compositæ. It may be wondered how the distribution of the vegetation has originated. That the Australian continent has risen slowly, is gathered from numerous proofs, among others the very apparent one of the strata exhibiting preponderately a horizontal pline. It may further be inferred that in its uplifting, the outer rim of the continent was slightly more elevated than the interior. This taken into consideration along with what doubtless at one time existed, namely, a great inland $s \in a$, abundance of marshes and mud, and a once probable greater rainfall, and particularly the latter, though one and all may have contributed to the present physical features, and consequently plant life. Another interrogatory arises, viz. Whence the coal-seams? As to these, there is some likelihood they are the remains of vegetation borne hence from a now surken conti. nent eastward of Australia ; New Zealand, Norfolk, and Howes Island being outliers or now mere island vestiges of the said great land area in the Pacific Ocean.

Of the four local divisions above enumerated, the most typical vegetation of the fir $t$ is the group Proteacex, a very ancient family, extending back to the secondary period of geology, from which time Australia apparently has never been submerged. A point of very considerable importance as bearing on this longcontinued stability of the Australian continent may be derived from the remarkable cluse relationship and insensible gradation of some plants ; for instance there is great difficulty in separating species of Eucalypti, Banksias, \&c. Thus it may be said none or few of the connecting links have been lost, as must necessarily have been the case had submergence and elevation of the land have occurred.

Many curious problems yet await investigation, such as the fertilisation of the Proteads, including the Styleworts and Goodenia family. Again, have the Epacrids once been a family of trees, wherefrom the living species are but decadent examples? The Casuarinex, or Beefwod tribe, are u idoubtedly an ancient group, and like conifers, flourished in the dawn of life. The second division of the eastern sl pes, Palins, and Tree-nettles possibly may have had an Asiatic origin, through the Malayan Archipelago. They appear not to be truly Australian in origin, but themselves only lung established celonists. $O_{12}$ the costrary, among the third divi ion of the cold mountain scrub; the Dorophoræ (Sassafras) hold a con. spicuous place, and evidently are of Australian derivation. The peculiar vege ation of the interior plains or fourth division, the Chenopods and the Compositæ, are rapidly becuming one of the past, and the small species even now are sensibly giving place to the introduced grasses and weeds. Apart from the groups mentioned as most typical of the four areal divisions in question, as regards the Acacias and Eucalypt;, they have the widest distribution and complicated genera. They both appear to be genera at their zenith, having exi,ted long enough to pass into redundant forms, but not long enough to have been exposed to vicissilude; and decline. Their absence from Howe's Island and New Zealand shows they in all likelihood did not belong to the hypothetical submerged continent, nor are they old enough to be fuund along with the lanrel and other remains of the gold drift. (Abstract of a communication by Mr. Robert Fitzgerald, F.L.S., read at the meeting of the Linnean Society, February 2, I882.) \section{UNIVERSITY AND EDUCATIONAL
INTELLIGENCE}

CAMBRIDGE.-The recent report of the Council of the Senate relative to the proposed Frosessorship of Animal Morphology, is creditable both to the University and to the Council. We think it desirable to quote some of its paragraphs entire. "The successful and rapid development of biological teaching in Cam. bridge, so honourable to the reputation of the University, has been formally brought to the notice of the Council. It appears that the classes are now so large that the acconmodation provided but a few years ago has already become insufficient, and that plans for extending it are nuw occupying the attention of the Museums and Lecture-Rooms Syndicate.

"It is well known thai one branch of this teaching, viz., that of Animal Morphology, has been created in Cambridge by the efforts of Mr. F. M. Balfour, and tla: it has grown to its present importance through his abili.y as a teacher and his scientific reputation.

"The service to the interests of natural science thus rendered 
by Mr. Balfour having been so far genercusly given without any adequate academical recognition, the benefit of its continuance is at present entirely unsecured to the University, and the progress of the deparimeat under his direction remains liable to sudden check."

It is recommended that a Professorship of Animal Mythology shall be established, terminable with the tenure of the first Professor; the stipend to be $300 \%$. a year; the Professor to be appointed by vote of members of the Senate on the Electoral Roll. The duty of the Professor is defined as "to teach and illustrate the principles of the structure and development of animals, to apply himself to the advancement of the knowledge of those subjects, and to promote their study in the University." The Grace will be proposed on May II.

From the reports of the natural science examiners in the last Local Examinations, we learn that the Junior Chemistry paper was very feebly answered, many being unable to explain the difference between a chemical comprund and a mechanical mixture; but the practical work was satisfactorily done. The senior boys did well in chemistry, though the girls did badly. In heat, there were many failures among the Juniors, with great want of exactness in the definition of important terms: the majority failed to do a very simple calculation concerning the expansion of a solid; the Seniors did better. In Statics and Hydrostatics the papers of the Juniors were unsatisfactory; the answers to one numerical question were mostly confused masses of figures without a single word to serve as a clue to the labyrinth. The Seniors also receive a bad report; the questions involving accurate definition were not either attempted or were poorly done. In Botany the Junior papers were moderately good; there was, however, a tendency to the indiscriminate use of technical terms without a due regard to their meaning. The Seniors in many cases showed complete ignorance of sore of the most elementary facts; the description of specimens was especially bad. In zoology both Juniors and Seniors did fairly well; still there was a general absence of diagrams, and little evidence of practical work. One valuable remark of the examiner is that young scholars should not be informed of the erroneous ideas of the older naturalists, even though the errors are pointed out, as unnecessary trouble is thereby given, and confusion is likely to be caused. In Physical Geography, good papers were sent up; but in Geology the majority were altogether unsatisfactory.

The examination for a vacant Sheepshanks Astronomical Exhibition will be held in Lecture Rcom No. 7, at Trinity College, on Monday, April 24.

The Demonstrator of Comparative Anatomy will take an advanced class for instruction in the Sauropsida next term, beginning April 18.

EDINBURGH.-At the close of his lecture on Friday, 3ist ult., Prof. Archibald Geikie was presented with an illuminated address by past and present students of the Geology class in the University of Edinburgh. Mr. John Murray, of the Challenger Expedition, presented the address, which was as follows :-

"Sir, - We, your present and former students in the University of Fdinburgb, beg to pay you the tribute of a brief farewell. While rejoicing in the honour conferred on you by your appointment as Director-General of the Geological Survey of Great Britain and Ireland, we would record, along with the expression of our most hearty congratulations, our deep sence of the loss which both we and our Alma Mater will sustain by your de. parture. To the distinguished services you have rendered the seience in which you have taught us to share your interest and enthusiasm, we will do no more than refer; though we cannot fail to remember with pride how signally you have maintained the reputation of the Scottish School of Geology, and of Edinburgh, its metropolitan seat. We would here simply recall the many happy hours we have spent with you, both in the geological class-room and in the field, and express, for ourselves and for others now scattered over the world, the feelings of gratitude and affection with which your name will ever be regarded. We are, sir, with much respect and affection."

Having read the address, the sentiments of which were warmly applauded, Mr. Murray said that Prof. Geikie would find in it the names of abont 140 students, and they expected that a number more would yet be added. They did not intend the address to express all the deep feelings they had towards Pro. fessor Geikie, nor did they attempt to say all that one should wish about the admiration in which they held Prof. Geikie as a scientific man and as a teacher. Upon the face of the address were some sketches by one of his present pupils, which might serve to remind him of the instruments with which they had fought, and of some of the battle-fields upon which they bad been employed together-ergaged in a fight in which the students knew Prof. Geikie had been a most excellent general for them. After mentioning that a casket for the address would be presented at a social gathering to be beld in a few weeks thence, Mr. Murray, in name of the past and present pupils of the class, wished the Professor health, strength, success, and distinction in the new sphere of work to wbich he had been transferred. Prof. Geikie, who was warmly applauded, said there were moments in a man's life when the depth of his emotion was best expressed by silence. Therefore he made no attempt to tell the students how much their kindly feelings always, and this especially hearty outburst, had touched every fibre of his heart. At the close of every session he had been accustomed to look forward to the final day with great depression of spirits. It had always been to him a sad thing to say "good-bye" to the young men with whom he had been brought into such close personal contact during the winter; but this was to be his last adieu to them, and he could hardly trust himself to share into words the feeling of genuine sorrow with which be left that class-room. Eleven years ago he began the work of that class. The Chair of Geology in the University was founded by the munificence of Sir Roderick Murchison, who was struck down by illness before the arrangements for the foundation were completed, and be believed it was largely due to the present Parliamentary repre sentative of the University, Dr. Lyon Playfair, that these arrangements were finally carried out. As the students had said in the address, bis aspirations had been very strong towards reviving, as far as in him lay, the fame of the Scottish School of Geology, No one could be more sensible than he was, of how far he had fallen shert of the aspirations with which he began his work. But although he did not for a moment attempt to justify his failures, he should try to show them how difficult his task had sometimes been. When he entered on bis duties, there was not one diagram or specimen belonging to this class. He had to obtain diagrams from all sources, and to make many of them himself, there being no great endowment for the support of the Chair. One part of his work during the eleven years had been to gather together materials for a class-museum. These he had succeeded in obtaining, partly through purchase, and partly through the kindness of friendly benefactors to the University. This collection, which would be of the greatest value in the future work of the Chair, was at present in great part stowed away in boxes, for want of space to display it. $\mathrm{He}$ had much satisfaction in leaving it as a legacy to his successor, Having referred to the difficulties which had attended the conducting of the class, arising from the deficiency of accommo. dation, two, and sometimes thre? professors using the same class-room, the Professor said this Chair was the first started in Scotland for the special cultivation of geology and mineralogy. He believed he was the first in Scotland, if not in Britain, to organise a practical class for the study of mineralogy and the microscopic investigation of rocks. Owing to the transference of the medical classes to the new University Buildings, his successor would have a series of class-rooms, with laboratory and museum attached, and he had no doubt a great future was in store for the prosecution of geology in the University of Edinburgh. He had tried always to make the cultivation of field-geology a prominent part of the work of the class; and some of their pleasantest associations bad been among the glens of the Highlands and the hills and shores of the lowlands. In concluding, Prof. Geikie thanked the students very heartily for their lindness in the past, and for this crowning mark of their regard. Though bis voice would no longer be heard within these walls, his interest in the students remained as sincere and as hearty as ever it was. They knew him well enough to be assured that his students had been, and always would be, to him personal friends. "And now, gentlemen," he concluded, "long live our dear old Alma Mater, anrl God bless you all."

Tre following is the award of the Public Schools' Prize Medals of the Geographical Society for 1882 :- Physical Geography (Examiner Prof. H. N. Moseley, M.A., F.R.S.): Gold Medal, Hlubert Llewellyn Smith, Bristol Grammar School; Silver Medal, Albert Richard Sharp, Dulwich College. Honourably mentioned: Andrew Claude Crommelin, Marlborough College; Montague Edward Fordham, London International College; Samuel William Carruthers, Dulwich College; Albert Lewis Humphries, Liverpool College. Political Geography (Examiner, Sir Artbur Blyth, K.C.M.G., Agent-General for 
South Australia) : Gold Medal, Frank Herman Becker, Dulwich College; Silver Medal, Sydney Charles Farlow, Harrow School. Honourably mentioned: Robert Galbraith Reid, Dulwich College.

\section{SCIENTIFIC SERIALS}

Fournal of the Franklin Institute, February. - On the behaviour of steam in the steam-engine cylinders, and on causes of efficiency, by R. H. Thurston.-What is the most economical point of cut-off for steam-engines, considered as a question of finance? $1 \mathrm{y} \mathrm{W}$. D. Marks. - Contribution to the history of the link motion, by J. L. Whetstone.--A new theory of the suspension system with stiffening truss, by A. J. Dubois.-Steamship performance, by J. W. Nystrom.-Radio-dynamics; atomic phyllotaxy and kindred harmonies, by P. E. Chase.

Bulletin de l'Académie Royale des Sciences de Belgique, No. 12, 1881. - On the probable cause of variations of latitude and terrestrial magnetism, by F. Folie.-Remarks on the electric phenomena which accompany variations of the potential energy of mercury, by G. Van der Mensbrugghe.-On compound ethers of hyposulphurous acid, by W. Spring and E. Legros.-On the action of chlorine in sulphonic combinations, and on organic oxysulphides, by W. Spring and C. Winssinger.-On the action of chlorine on tertiary butylic alcohol, by Baron d'Otreppe de Bouvette.-On the structure of gemmiform pedicellaria of Spharechinus granularis and other Echinida, by A. Fottinger. - Researches on the organisation and development of Orthonectides, by C. Julin.-On the respiratory oscillations of the arterial pressure in the dog, by L. Fredericq. - On the delimitation and constitution of the lower coal-formation of Belgium, by J. C. Purves,-On the oscillations of blood-pressure called Periods, of Traube-Hering, by L. Fredericq. - A page of the history of a whale, or cetology fifty years ago: lecture by P. J. Van Beneden.-History of astronomy in Belgium: lecture by $F$. Folie.

Reale ${ }^{2}$ stituto Lombardo di Scienze e Lettere. Liendiconti, vol. xv. fasc. iii.-Meteorological résumé of the year I88r, calculated from observations made in the Royal Observatory of Boera, by E. Pini.-On the achromasia of aphaneri (i.e. colourlessness of certain minute organisms), by L. Maggi. - On the toxical action of hydroxylamire, by C. Raimondi and G. Bertoni.

Atti della R. Accademia dei Lincei, vol, vi, fasc. 6.-On Hieratite, a new mineralogical species, by A. Cossa.-On monobromopyridine, by L. Danesi.-Observations in addition to the memoir entitled "On an Organ of some Vegetable Embryos," by $\mathrm{G}$. Briosi.-On the extraordinary atmospheric pressure of January, I882, by L. Respighi.

Bulletins de la Société d'A Anthropologie de Paris, tom. iv. fasc. iii., I88I. - M. Thulié concludes his paper on the differences between the true Bosjesmans and Hottentots, the former of whom he regards as survivors of an aboriginal, and once predominant race. - M. Topinard's report of his observations on the indigenous races of Algeria during a brief sojourn in that provinee, has given occasion-through his disregard of his own rules of ethnological inquiry, and his hastily formed views based on mere appearance - to the most interesting of the papers and discussions reported in these Bulletins. Among these are the comprehensive expositions which $M$. Topinard gave at a subsequent meeting of his "Méthode d'observation sur le vivant à propos de la discussion sur l'Algerie," and the description of his own modification of "Broca's Goniometer for measuring Cuvier's facial angle on the living subject."-M. Sabatier, in a paper on the different appellations used by the ancients to designate the peoples of Africa, endeavours to prove the existence of close analogies between Sanskrit, Greek, and the Berber dialect, as shown in the names of leading African peoples, which he derives either from their predominant accupations, or the nature of the region in which they dwelt.-M. Ameghino describes the result of his recent explorations of the Chelles beds, in which no human remains have been found, while those of the elephant, rhinoceros, and cave-bear are numerous, together with an abundance of aqueous, but no terrestrial shells.-M. Cavaroz reports his discovery of an atelier of flint implements in the Jura, near Salines, which appears to belong to the Neolithic age.-M. le Baron presented his report on prehistoric osseous lesions, which forms the subject of his inaugural thesis, and is based on a study of the specimens contained in the Broca, and the Society's,
Museum. The list of diseases includes most of the modern forms, common in infancy and advanced age, while the numerous instances of trepanning, and the not infrequent cases of well consolidated fractures show that primæval man was not wholly negligent, or unskilled in regard to surgical metbods.-A new case of so-called hermaphrodism reported by M. Magitot, gave rise to considerable discussion, in the course of which it was agreed that the use of the term was not in harmony with the present state of physiological inquiry, and that the abnormalities in question ought to be included under the general head of malformations, or embryonic arrest of development.-We have further to notice papers by Madame Clemence Royer, on "Le Bien et la loi Morale"; by M. Zaborowski on the memory and its distur. bances; by Mr. Foley, on the relations between the mode of life and character of tropical peoples, and the humid climate in which they live; and finally, two highly important communications, received from $\mathrm{M}$. de Ujfalvy, on the craniometric and other measurements made by him while travelling in the Thibetian, Kashmir, and other Indian territories. His observa. tions on the Baltis, Lhassas. Ladakis, Koulous, and Lahoulisthe two last-named of which practise polyandry, and follow a degraded form of Bouddhism-supply highly interesting, and hitherto unknown materials towards our better acquaintance with the ethnological and sociological history of these tribes.

\section{SOCIETIES AND ACADEMIES LONDON}

Royal Society, March 9, I882.- "On the Spectrum of Carbon," by G. D. Liveing, M.A., F.R. S., Professor of Chemistry, and J. Dewar, M.A., F.R.S., Jacksonian Professor, University of Cambridge.

Angstrom and Thalén, in their memoir "On the Spectra of the Metalloids" (Nova Acta Reg. Soc. Upsal., Ser. iii. vol. ix.), give a map and table of wave-lengths of the lines due to carbon in the visible part of the spectrum, as distinguished from the fluted spectra given by compounds of carbon, namely, carbonic oxide, cyanogen, and acetylene. These lines, they state, always appeared when very powerful induction sparks were passed through the vapour of any compound of carbon, or between carbon electrodes. This line-spectrum is remarkable for simplicity, consisting of eleven lines, of which the single line in the yellow, followed by a triple group in the green, and a very strong line in the blue, recall vividly the spectrum of mag. nesium ; and as we know two modifications of the spectrum of magnesium which seem to be due respectively to the oxide and a hydride, the parallel between the behaviour of the two elements is the more striking.

The authors figure the ultra-violet spectrnm of carbon to a scale of wave-lengths within the range of the rays transmitted through calcite. The lines figured have been observed in photographs of the spark of a large induction coil, having a large Leyden jar in connection with the secondary coil, between poles of purified graphite in air, carbonic acid gas, hydrogen, and coal-gas. The same lines have been observed in photographs of the spark between iron, and between aluminium poles in carbonic acid gas. By comparing the photographs taken under these different circumstances, they have, they believe, eliminated the air-lines, which are numerous and strong in the region between $\mathrm{H}$ and $\mathrm{T}$, and also the metallic lines which graphite, purified with the utmost care, still exhibited.

The graphite was purified by being stirred in fine powder into fused potash, and subsequent treatment with aqua regia, by prolonged ignition in a current of chlorine, and by treatment with hydrofluoric acid. The well-washed powder was afterwards compressed into blocks by hyd:aulic pressure between platinum plates, and from these blocks the electrodes employed were cut. Notwithstanding the purification, the photographs of the spark between these electrodes still showed very distinctly lines of magnesium and iron.

The wave-lengths of the strongest carbon lines were determined by means of a Rutherford diffraction grating having $\mathrm{I} 7,296$ lines to the inch. The measures were made in the following way:-A small photographic slide, containing the sensitive plate, fitted the telescope in place of the eye-piece, and so could easily bc turned about an axis coincident,, or nearly so, with the optic axis of the telescope. In taking a measurement of the position of a line the approximate wave-length was first found by interpolating between the nearest cadminum or other lines of known wave-length in photographs taken with calcite prisms. 